\title{
Image
}

\section{Gastric Lesion in a Patient with Advanced Hepatocellular Carcinoma}

A 57-year-old male was diagnosed to have multifocal advanced hepatocellular carcinoma 1 year back and was on medical therapy. The patient presented at emergency with melaena upper gastrointestinal (GI) endoscopy demonstrated these lesions in antrum. What is the diagnosis?

The patient has been on Sorafenib $200 \mathrm{mg}$ twice a day for almost 1 year. Upper GI endoscopy shows multiple geographic ulcers in antrum [Figure 1] radiating from pylorus almost like spokes of a wheel. There are likely to be drug-induced ulcers. Similar ulcers have been described earlier in GI tract though rare in the stomach. ${ }^{[1,2]}$ These lesions are distinct from Gastric antral vascular ectasia which are more common in patients with chronic liver disease. The patient was

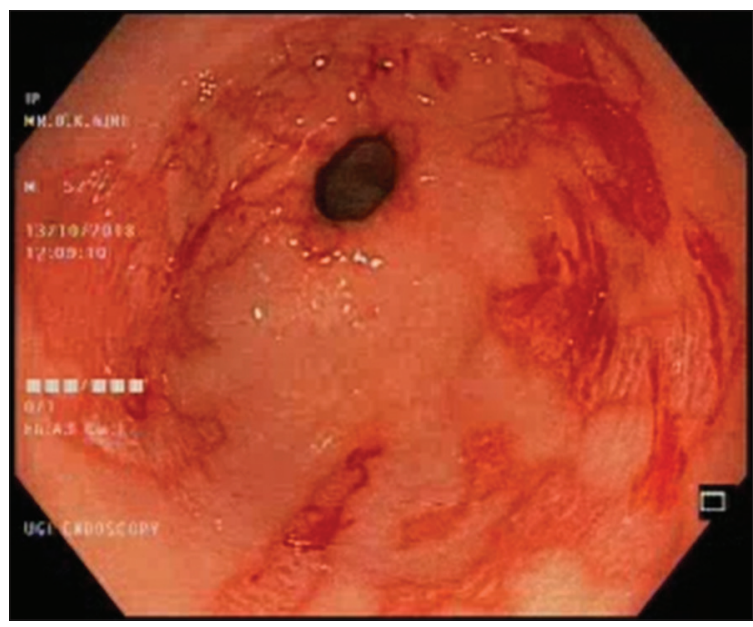

Figure 1: Endoscopy showed multiple geographic ulcers in antrum

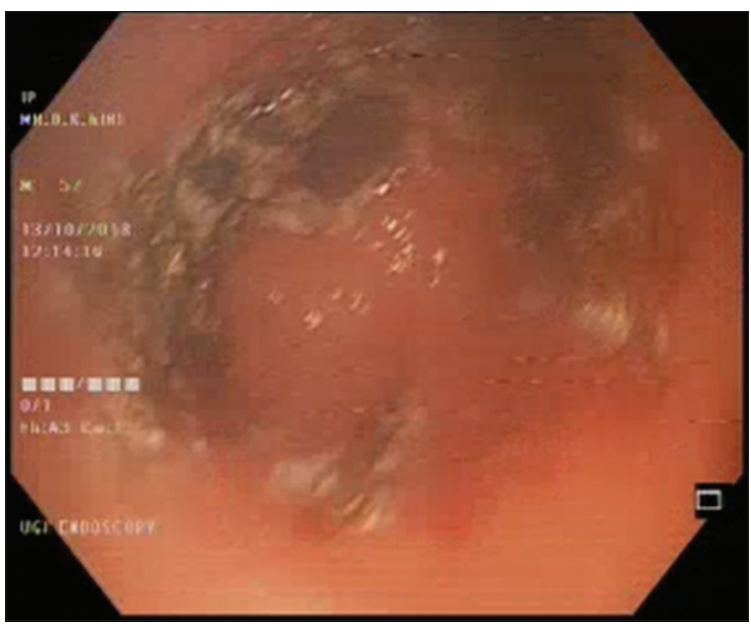

Figure 2: Endoscopic image post Argon Plasma coagulation treated by argon plasma coagulation [Figure 2] along with supportive treatment.

\section{Declaration of patient consent}

The authors certify that they have obtained all appropriate patient consent forms. In the form the patient(s) has/have given his/her/their consent for his/ her/their images and other clinical information to be reported in the journal. The patients understand that their names and initials will not be published and due efforts will be made to conceal their identity, but anonymity cannot be guaranteed.

\section{Financial support and sponsorship}

Nil.

\section{Conflicts of interest}

There are no conflicts of interest

Subhash Chandra Tiwari, Rachit Agarwal, M. K. Goenka Institute of Gastrosciences and Liver, Apollo Gleneagles Hospitals, Kolkata, West Bengal, India

Address for correspondence: Dr. M. K. Goenka, Institute of Gastrosciences, Apollo Gleneagles Hospitals, Kolkata, 58 Canal Circular Road, Kolkata, West Bengal, India E-mail:mkgkolkata@gmail.com

\section{REFERENCES}

1. Kameda R, Ueno M, Kobayashi S, Ohkawa S. A case of multiple ulcer in the descending part of the duodenum following sorafenib administration for hepatocellular carcinoma. Dig Endose 2012;24:A2.

2. Kang HY, Moon SH, Song IH. A unique bleeding-related complication of sorafenib, a tyrosine kinase inhibitor, in advanced hepatocellular carcinoma: A case report. J Med Case Rep 2014;8:72.

This is an open access journal, and articles are distributed under the terms of the Creative Commons Attribution-NonCommercial-ShareAlike 4.0 License, which allows others to remix, tweak, and build upon the work non-commercially, as long as appropriate credit is given and the new creations are licensed under the identical terms

\begin{tabular}{|l|l}
\multicolumn{2}{c}{ Access this article online } \\
\hline Quick Response Code: & Website: www.jdeonline.in \\
& \\
\end{tabular}

How to cite this article: Tiwari SC, Agarwal R, Goenka MK. Gastric lesion in a patient with advanced hepatocellular carcinoma. J Dig Endosc 2018;9:210. 